\title{
Monitoring of UV spectral irradiance at Thessaloniki (1990-2005): data re-evaluation and quality control
}

\author{
K. Garane, A. F. Bais, S. Kazadzis, A. Kazantzidis, and C. Meleti \\ Laboratory of Atmospheric Physics, Aristotle University of Thessaloniki, Thessaloniki, Greece \\ Received: 19 June 2006 - Revised: 1 December 2006 - Accepted: 6 December 2006 - Published: 21 December 2006
}

\begin{abstract}
We present a re-evaluation and quality control of spectral ultraviolet irradiance measurements from two Brewer spectroradiometers operating regularly at Thessaloniki, Greece. The calibration history of the two instruments was re-examined and data flaws were identified by comparing quasi synchronous measurements. Analysis of the sensitivity of both instruments to variations of their internal temperature revealed that they have temperature coefficients of different sign. These coefficients exhibit small variability during the 15 -year period. Using averaged temperature coefficients, we corrected both datasets. Corrections were applied for the angular response error using two different approaches depending on the availability of required ancillary data. The uncertainties associated with the measurements have been estimated and presented. Finally, the two datasets are compared using ratios of irradiance integrals at various bands in the UV, in order to assess any dependencies on the internal instrument temperature, solar zenith angle and wavelength.
\end{abstract}

Keywords. Atmospheric composition and structure (Instruments and techniques) - Solar physics, astrophysics and astronomy (Ultraviolet emissions; Instruments and techniques)

\section{Introduction}

Following the discovery of the Antarctic ozone hole in the mid 1980's, there has been an increased scientific and social interest in the state of stratospheric ozone levels, on a global scale. Apart from the ozone depletion in Antarctica, there was strong evidence that stratospheric ozone was diminished also at mid-latitudes (Harris, 1997). While ozone depletion continued in the 2000's at the polar regions, at

Correspondence to: K. Garane

(kgarane@physics.auth.gr) mid-latitudes it has been leveled off, although it remains still lower compared to the ozone amounts in the 1970s (Metz et al., 2005). If all other factors affecting UV (e.g. clouds, aerosols, albedo, etc.) remain stable, reductions in atmospheric ozone can lead to increases in UV irradiances at the ground, particularly at wavelengths less than $320 \mathrm{~nm}$. Potential increases in solar UV radiation raise concern because of its detrimental effects on humans, plants, and animals (Andrady et al., 2006). Consequently, long-term monitoring of UV irradiances at the ground are essential for assessing the biological effects of UV and therefore a number of monitoring sites have been established, although coverage is by no means representative for the globe. Increases of UV radiation in response to reductions in total ozone at various sites and for various periods have been reported during the 1990s (Booth et al., 1994; Kerr and McElroy, 1993; Seckmeyer et al., 1994; Zerefos et al., 1997, 2001; Bartlett and Webb, 2000).

Of particular importance for determining accurately the variability of UV radiation and its long term changes, is the quality of the measurements. Many projects were accomplished and numerous studies were conducted with the aim to improve the quality of the measurements (Gardiner and Kirsch, 1992; Bais et al., 2001; Bernhard and Seckmeyer, 1999; Gröbner et al., 2005). Maintaining consistent quality assurance (QA) and quality control $(\mathrm{QC})$ procedures for the measurements from UV spectroradiometers and simpler radiometers is not an easy task, requiring substantial investment in laboratory facilities and labor. Lack of calibration procedures and standards that can easily be operated in the field with low uncertainties, makes the absolute calibration of spectroradiometers a still challenging task. Achieving and maintaining a reliable absolute calibration of a UV spectroradiometer is a complicated process, but this is the most important requirement in UV spectroradiometry. Some of the most significant sources of errors and uncertainties during the calibration procedure, using spectral irradiance standard

Published by Copernicus GmbH on behalf of the European Geosciences Union. 
lamps, are discussed in previous works (Bernhard and Seckmeyer, 1999; Bais et al., 1997a; Gardiner and Kirch, 1995). The accuracy in setting the current of the calibration lamp, the precision in setting the distance from the lamp, the stability of the conditions in the calibration room, reflections on surroundings and the positioning of the lamp are a few of the most common sources of uncertainty during the absolute irradiance calibration (Bernhard and Seckmeyer, 1999).

Aiming at the standardization of measurements and quality control procedures in UV spectroradiometry, the World Meteorological Organization has produced three documents with guidelines: Webb et al. (1998), Seckmeyer et al. (2001) and Webb et al. (2003). In addition, a series of post processing procedures have been developed aiming at the improvement of the spectral solar UV measurements' accuracy. These, include methods for correcting the measurements for angular response errors (Seckmeyer and Bernhard, 1993; Bais et al., 1998; Feister et al., 1996), for wavelength scale errors (Huber et al., 1993; Slaper et al., 1995; Slaper and Koskela, 1997), for temperature dependence (Weatherhead et al., 2001; Capellani and Kochler, 1999), for stray light rejection (Davies, 1996; Bais et al., 1997a) and for spikes (Meinander et al., 2003).

The UV monitoring station of Thessaloniki has one of the longest records of spectral UV irradiance measurements, from two Brewer spectroradiometers. In this paper, we present the re-evaluation of the UV spectral irradiance record of Thessaloniki, which was performed in order to further improve the quality of the measurements and the significance of their statistical analysis. We describe the methodology that was followed and the relevant $\mathrm{QA} / \mathrm{QC}$ procedures. The analysis of the measurements for their long-term variability is subject of another study that will follow.

\section{Instrumentation and history of measurements}

In this study we are concerned for spectral measurements of solar ultraviolet irradiance on a horizontal surface. The measurements were conducted by a single- (type MK II, with serial number 005) and a double-monochromator (type MK III, with serial number 086) Brewer spectroradiometers (Brewer, 1973; Kerr et al., 1984; Bais et al., 1996), which operate on a regular basis at the Laboratory of Atmospheric Physics, University of Thessaloniki, Greece. The single monochromator was installed in 1982 for the monitoring of total ozone and columnar sulfur dioxide. In late 1989, it was modified to conduct also spectral irradiance measurements. The double monochromator started its operation in 1993. Because it has been used a lot in experimental campaigns, its measurements' record has various gaps, occurring almost every year. During their operational period the two instruments recorded more than 156000 spectra.

Both Brewers are positioned side by side on the roof of the Physics Department building (latitude $40.634^{\circ} \mathrm{N}$, longti- tude $22.956^{\circ} \mathrm{E}$, altitude $60 \mathrm{~m}$ a.s.l.), in the center of the city of Thessaloniki. The horizon of their input optics is free to the South and West. Buildings and local obstructions block the East side up to an angle of $10^{\circ}$ and the north side up to an angle of $30^{\circ}$. These obstacles, which are present since the beginning of the measurements, reduce the diffuse irradiance by up to $2 \%$ for both instruments. The magnitude of this effect is within the measurements' uncertainties and due to the fact that it varies, depending on solar zenith and azimuthal angles, and on cloud and aerosol conditions, no correction has been applied to the spectral irradiance measurements.

The operational wavelength range of Brewer \#005 is 290$340 \mathrm{~nm}$ and the nominal step of the spectral irradiance measurements is $0.5 \mathrm{~nm}$, while Brewer \#086 operates in the range $287.5-366 \mathrm{~nm}$ (step $0.5 \mathrm{~nm}$ ). The measurements of Brewer $\# 005$ above $325 \mathrm{~nm}$ are not used in the analysis because of the low sensitivity of the instrument at this wavelength range, which results in large uncertainties. For both instruments, the shape of the slit function is triangular with wings extending in both directions beyond $\pm 1 \mathrm{~nm}$ from the center wavelength (Bais, 1997a) and the FWHM (Full Width at Half Maximum) is equal to $0.55 \mathrm{~nm}$. The double monochromator consists of two conventional Brewer spectrophotometer optical frames, arranged so that the exit slit plane of the first one forms the entrance slit plane of the second. The second spectrometer recombines the spectrum dispersed by the first reducing the amount of the out-of-band light (known as stray light) that reaches the final exit slit of the system (Bais et al., 1996). The diffraction gratings used in the double-monochromator Brewer are both operated in the first order and have a line density of 3600 lines $/ \mathrm{mm}$, whereas the grating in the spectrometer of the single Brewer has a density of 1800 lines $/ \mathrm{mm}$ and is operated in the second order.

The monitoring site of Thessaloniki is equipped, among other instruments, with two erythemally weighted radiometers, a UVB-1 radiometer by Yankee Environmental Systems Inc. (http://www.yesinc.com/) and a UVB Biometer 501 by Solar Light Co. (http://www.solarlight.com/), a UVA radiometer by EKO (http://www.eko.co.jp/) and a CM21 pyranometer by Kipp \& Zonen (http://www.kippzonen.com/). Data from these instruments are recorded as 1-min averages and, for the purposes of this work, are used for the quality control of the spectral measurements.

\section{Calibration history}

\subsection{Absolute calibration and stability checks}

Each of the spectroradiometers is equipped with an internal 20 Watt standard quartz halogen lamp that is sampled at least twice a day, and it can be used for coarse daily stability checks. Furthermore, an internal mercury discharge lamp is used for checking the wavelength calibration of the spectral measurements, and is usually measured before each 


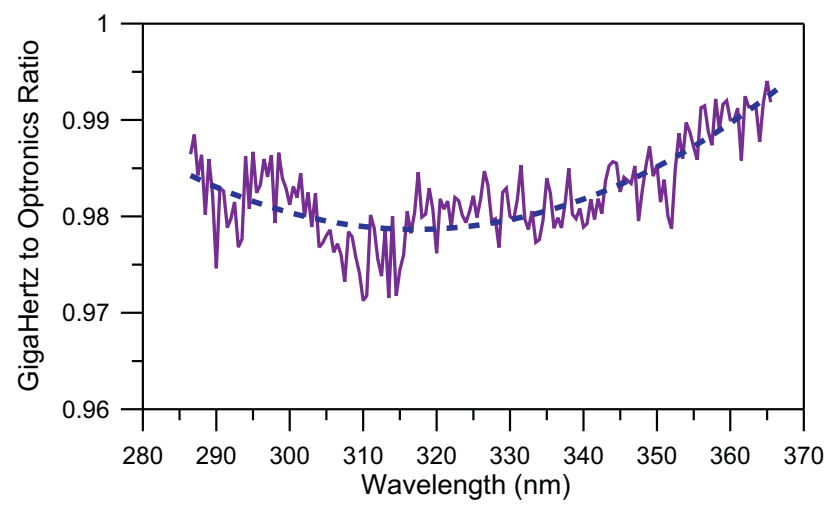

Fig. 1. The GigaHertz to Optronics irradiance scale ratio, as determined in 2002, when two new spectral irradiance lamps were obtained from each laboratory. The dashed line is the 2nd degree polynomial fit of the ratio.

spectral solar irradiance scan. The stability of the instruments is also monitored once a week using a set of five $50 \mathrm{~W}$ quartz halogen lamps that are mounted at a fixed distance above the instruments' diffusers. Usually, two or three different lamps are measured each time for consistency checking. Since 2002, the schedule of the lamp measurements has been modified. The same pair of lamps from the set are measured every week, together with a third one which is different every time. Thus, the first two lamps are used for monitoring the stability of the instrument from one week to another, while the third lamp is used as a link to the past measurements. The $50 \mathrm{~W}$ lamp measurements are performed outdoors, where the instruments operate regularly.

The main calibration sources of spectral irradiance that were used in the Laboratory of Atmospheric Physics, since the early 1990s were obtained and calibrated by Optronics Laboratories, and thus they were traceable to NIST (National Institute of Standards and Technology, http://www.nist.gov/), standards. Since 2002, the main calibration sources are supplied by GigaHertz Optik, who traces their calibrations to PTB (Physikalish - Technische Bundesanstalt, http://www. ptb.de/), Germany. To avoid an abrupt change in the measurements record, we adjust spectrally the scale of the PTB lamps by a function that was determined in 2002, when two irradiance standards were obtained, one from each Laboratory. The function that is displayed in Fig. 1 resulted from the direct comparison of the two calibrated lamps that were measured at the same day by Brewer \#086, and represents the spectral difference between the two specific lamps that were delivered by the two Laboratories. The dashed line is a 2nd degree polynomial fit of the "GigaHertz over Optronics" ratio. This fit is used regularly since 2002 to adjust the irradiance scale of the GigaHertz lamps to the Optronics Laboratories scale. It appears from Fig. 1 that the spectral differences between the two calibration standards range between $-1 \%$ and $-2 \%$, depending on wavelength. The providers of the

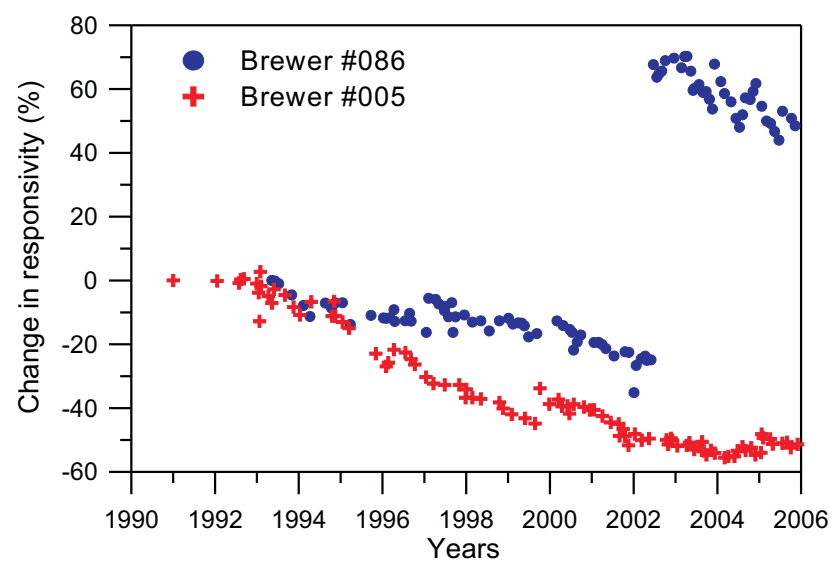

Fig. 2. Time series of the percentage change in the responsivity of the two Brewer spectroradiometers at $320 \pm 5 \mathrm{~nm}$, with respect to the first calibration in their records. The calibration factors have been corrected for temperature effects to a standard temperature of $25^{\circ} \mathrm{C}$.

$1000 \mathrm{~W}$ calibration standard lamps quote an uncertainty of $\pm 1 \%(1 \sigma)$ for the UV range, whereas an additional $\pm 1.5 \%$ should be expected from the transfer of the calibration to our working standards.

The absolute irradiance calibration of the two Brewer spectroradiometers is performed once a month - or sooner if necessary -, using $1000 \mathrm{~W}$ DXW tungsten-halogen working standard lamps. Every six months, a main calibration source of spectral irradiance (1000 W DXW) is used along with the working standards. Thus the working standards are re-calibrated at least every six months.

Almost every two years, the relation between the stepper motors of the gratings and the measured wavelength is determined by scanning the emission lines of spectral discharge lamps (Hg, Cd and Zn) (Gröbner et al., 1998). The wavelength calibration is checked many times a day by scanning an internal $\mathrm{Hg}$ lamp. The application of the SHICrivm algorithm (Slapper et al., 1995) shows that the wavelength shifts of the spectral measurements are of the order of $\pm 0.1 \mathrm{~nm}$ at $305 \mathrm{~nm}$ and $\pm 0.05 \mathrm{~nm}$ at $320 \mathrm{~nm}$, for both instruments.

The calibration history of the two instruments is shown in Fig. 2, as percentage changes of the calibration factor at $320 \pm 5 \mathrm{~nm}$, with respect to the first calibration. The calibration factors have been corrected for the effect of temperature variations to a standard temperature of $25^{\circ} \mathrm{C}$. The abrupt increase in the calibration factor of Brewer \#086 on 27 June 2002 is due to the replacement of one of the gratings. Smaller fluctuations in the calibration factors are attributed to changes in the sensitivity of the photomultiplier, as well as to changes that were caused during servicing or repairs. Especially for Brewer \#086, changes have been reported after its transportation to take part in experimental campaigns. The systematic decrease in the calibration factor of Brewer \#086 through the years, at this wavelength range, is approximately 


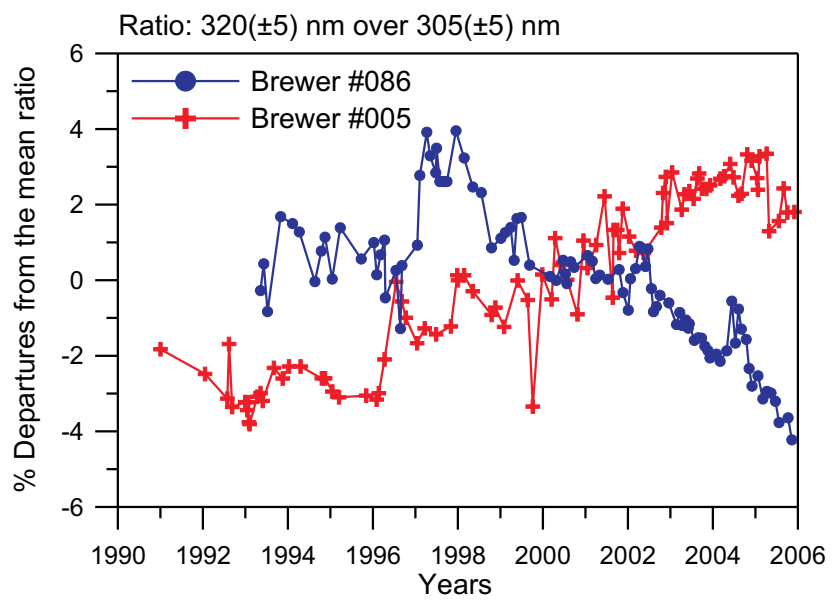

Fig. 3. The spectral variation of the calibration factors of Brewers \#005 and \#086, throughout the period of their operation, expressed by the ratio of the calibration factors at $320 \mathrm{~nm}( \pm 5 \mathrm{~nm})$ and $305 \mathrm{~nm}$ $( \pm 5 \mathrm{~nm})$.

$25 \%$ for the period $1993-2002$ and about $23 \%$ for the period 2002-2005. If the replacement of the grating in 2002 had not occurred, the overall degradation of the instrument's sensitivity would have been about $43 \%$ in a period of 13 years. The corresponding degradation of the sensitivity of Brewer \#005 is close to $55 \%$ in 16 years of operation. These percentages of degradation are probably an aging effect of the different optical components of the instruments, including the diffuser. The effect of the degradation on the actual measurements is negligible, since the reduction in the sensitivity has been implicitly taken into account in the absolute calibration factor.

Sometimes, the responsivity of the spectroradiometers changes not only in absolute sense, but also spectrally. The spectral stability of the responsivity of Brewer \#005 and \#086 is shown in Fig. 3, indicatively as the departure, in percent, from the mean ratio of the calibration factors averaged over two different wavelength bands: $320 \pm 5 \mathrm{~nm}$ and $305 \pm 5 \mathrm{~nm}$. Despite the sudden fluctuations that appear during the record, the general pattern for Brewer \#005 is a systematic increase in the ratio of about $7.4 \%$ during its period of operation, which suggests a faster decrease in the sensitivity at short wavelengths. Part of the variability of this ratio results from the large decrease in the sensitivity of the MK II type Brewers at wavelengths longer than $320 \mathrm{~nm}$, which leads to an increase in the random noise. On the contrary, Brewer \#086 appears to be quite stable from the start of its operation until early 1997, when the removal of the UG11 bandpass filter, caused an abrupt increase of the ratio by $\sim 2 \%$. The systematic decrease of the spectral ratio for the double monochromator, since 1998 until now, is about $8 \%$ and it denotes that the sensitivity decreases faster at long, than it does at short wavelengths.
The fluctuations of the ratios coincide with changes in the optical alignment of the spectrometers and other service actions, which usually result into wavelength dependent changes in the throughput of the spectrometers. As with the changes in the absolute responsivity of the instruments, these wavelength dependent changes in their sensitivity, affect also the calibration factors and therefore they are also taken into account implicitly when the actual irradiance measurements are processed.

\subsection{The re-evaluation procedure}

The calibration history of the two Brewer spectroradiometers was recently re-evaluated and the quality control of their measurements was revisited. The re-evaluation was considered necessary, since after so many years of operation we have obtained a better insight on the stability of the instruments and more experience concerning their long-term behaviour. The re-evaluation procedure consists mainly of a) the recalculation of the calibration factors after cross checking the behaviour of the calibration lamps during the entire period of the record, b) the intercomparison of synchronous measurements of the two instruments, and c) the comparison of the measurements of the two Brewers with those obtained by a collocated erythemal radiometer and a pyranometer.

As the two Brewers operate unattended and automatically, their measurements are occasionally affected by the mispositioning of the iris, the filters or the director prism, or by the loss of wavelength calibration, especially after power breaks. Any false measurements that have not been detected during the regular quality control, become clearly evident when comparing synchronous measurements, and are removed from the dataset, unless they can be corrected.

The first step of the quality control methodology was the correction of the raw data for extreme values (spikes) at single wavelengths, following a methodology developed at our laboratory, which is similar to the one described by Meinander et al. (2003). Afterwards, a day-by-day inspection of the internal standard lamp irradiance measurements was performed. The standard lamp irradiance depends strongly on temperature, which, however, is also recorded and can be taken into account when comparing measurements performed at different times in a day. From the temperature corrected standard lamp measurements, major momentary or longer-term changes in the instruments' behaviour could be detected. Occasionally, it was possible to apply appropriate correction factors, depending on the nature of the problem (e.g. mispositioning of a filter or the iris). When a change of less than $\sim 10 \%$ in the standard lamp measurements was detected without any profound reason, the respective spectra were flagged and they were re-examined during the next steps of the quality control procedure, otherwise, these spectra were discarded.

The spectral calibration factors of the instruments are derived both from the main calibration sources and the working 
$1000 \mathrm{~W}$ standard lamps. The $50 \mathrm{~W}$ lamp scans are used mainly for tracking any prominent changes in the sensitivity during the period between subsequent absolute calibrations. If such a change could not be accounted by the two absolute calibrations, performed before and after the change, the $50 \mathrm{~W}$ lamp scans were used to produce the spectral calibration factor for the corresponding period.

The quality control of the spectral irradiances recorded by the two spectroradiometers, as far as their long term stability is concerned, was achieved by comparing all spectra that were recorded almost synchronously by the two spectroradiometers. The average irradiance in the wavelength band $305-325 \mathrm{~nm}$ was chosen for the comparison, because both instruments have their highest sensitivity in this spectral range. A ratio of measurements was formed only when the two measurements (one from each instrument) were synchronous within one minute and they were recorded under cloudless conditions during the whole scan, because the irradiance changes significantly with solar zenith angle (SZA), and thus with time, and under variable cloud conditions. Ratios from measurements recorded under unstable weather conditions were used only qualitatively, when no clear-sky ratios were available in a day. The duration of a spectral scan is different for the two Brewers. Therefore the time stamp for each band was calculated as the mean of the measurement time of all wavelengths in the band. Scans with a difference in the mean time of less than 1 min were considered as synchronous. Under certain conditions, this interval is still large enough to introduce noise in the irradiance ratios, but it allows a sufficient number of ratios to be used. Selection of a smaller time difference leads to large gaps in the series, without affecting significantly the pattern of the time series of the ratios. In a few cases, visual inspection of these ratios uncovered changes in the sensitivity of the instruments that had passed the quality control checks. The changes were usually of the order of 2-4\% and in most cases application the calibration performed a few days later, could counter for the problem.

Continuous pyranometer measurements - with a time resolution of one minute - were used to flag all the scans recorded by the two instruments since 1993, for the stability of the radiation field caused mainly by clouds, using the methodology described by Vasaras et al. (2001). For the period 1989 to 1992 , no pyranometer measurements were available, so we applied a similar methodology using hourly measurements from a collocated UV-A radiometer. The irradiance ratios corresponding to clear sky conditions are less noisy, allowing easier detection of changes.

In addition to the irradiance ratios, we also used ratios of the erythemal irradiance as calculated from each scan, to the average of the one minute samples of a YES UVB-1 erythemal detector corresponding to the duration of the scan. These ratios were used mainly to attribute changes that were detected by examining the irradiance ratio of the two Brewers, to one of the two spectroradiometers. Moreover, these ratios were examined also on a day-by-day basis, separately for each spectroradiometer, in order to detect any remaining erroneous measurements. By using data from the erythemal detector we could inspect all the available spectra from both spectroradiometers, because the erythemal detector operates continuously and therefore there are always data to match a UV spectrum. Such comparisons were also useful in periods when one of the two spectroradiometers was not present or was not operating. For the period 1989-1992, when only the Brewer \#005 was operating, we used indicatively the measurements of the UV-A radiometer. Although the Brewer \#005 spectra cannot be matched with a UV-A instrument, still this comparison could indicate major changes in the sensitivity, especially under cloud-free conditions.

The sensitivity changes that were detected by the above procedures were used for the determination of the time period for which each calibration factor could be used, since it is very rare that a change in the sensitivity coincides with a calibration check. Such a coincidence only occurs when a repair, a maintenance work, or an intervention on the instrument is expected to be followed by a change in its sensitivity.

\section{Other corrections}

\subsection{Dark current, dead time and stray light}

Before converted to spectral irradiances, the raw measurements of the two spectroradiometers are first corrected for the dark current and the dead time of their photomultipliers, and using the integration time, they are converted into counts $\mathrm{s}^{-1}$. The count rates of the single monochromator are then corrected for the stray light effect, by subtracting the average irradiance measured in the band $290-292.5 \mathrm{~nm}$. This correction (Kerr and McElroy, 1993) is based on the assumptions that there is no real detectable radiation signal in this spectral region at the Earth's surface, and that the stray light effect is the same at all wavelengths. Therefore it should be expected that the correction may not remove entirely the stray light effect. Stray-light correction is not needed for the irradiance measurements of the double monochromator (Bais et al., 1996).

\subsection{Angular response}

Correction for the angular response error is necessary for both instruments. The angular responses of the two instruments are different, and therefore this error is apparent in the ratio of the uncorrected data. Two methods were used for the calculation of the angular response correction factors. The first method was applied on the Brewer \#086 data for the time period after 1996 and is based on the measured direct to global irradiance ratio. This methodology is described in detail in Bais et al. (1998) and cannot be used for the data before 1996 because measurements of the direct to global irradiance ratio were implemented after 1996. 


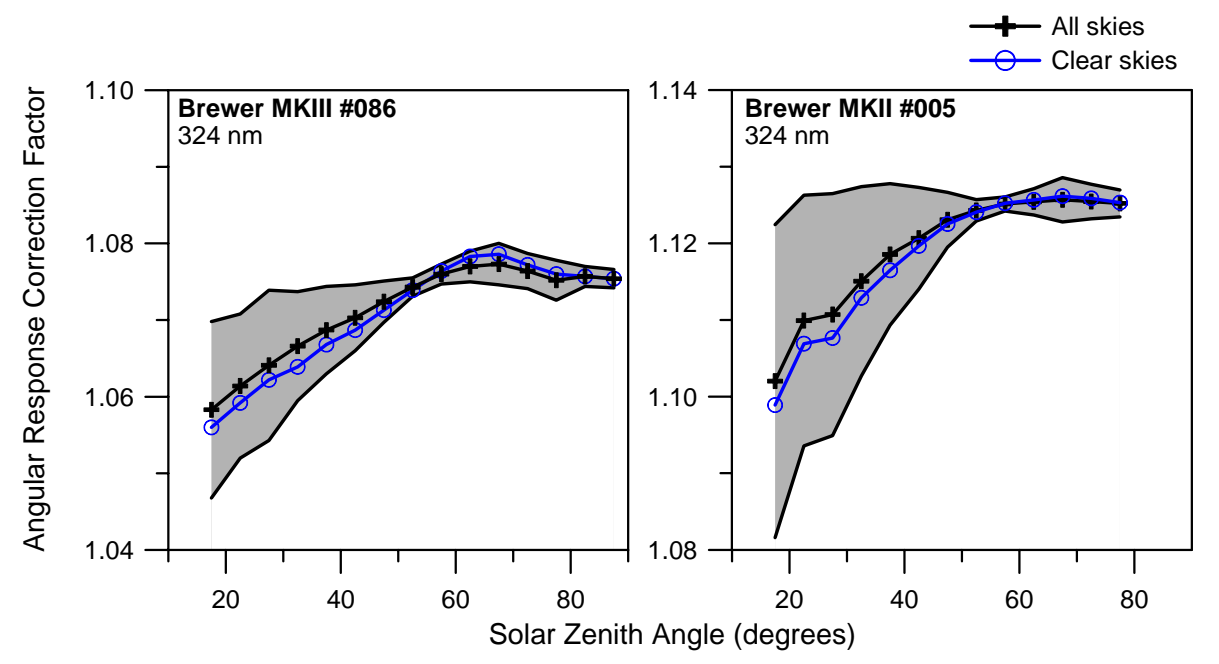

Fig. 4. Average correction factors for the angular response error of the two Brewer spectroradiometers at $324 \mathrm{~nm}$ under all skies (crosses) and clear skies (cycles), as a function of solar zenith angle. The shaded area represents the $1 \sigma$ variability for the all-sky average correction factor. The variability of the clear-sky correction factor is very similar and is not shown.

For the entire period of operation of the Brewer \#005 and between 1993 and 1996 for \#086, the angular response corrections are calculated using the UVSPEC radiative transfer model (Mayer et al., 1997), and the measured irradiances with an approximate angular response correction. The latter is based only on the diffuse irradiance correction factor, assuming also that the diffuse radiation is distributed isotropically (Bais et al., 1998). UVSPEC uses as input parameters the total ozone from collocated measurements or satellite overpasses, climatological values of aerosol optical depth, and the actual solar zenith angle for each spectral irradiance measurement. An effective cloud optical depth is calculated by comparing model-derived irradiances (convoluted to the slit function of the instrument) for different cloud amounts, with the measured irradiances (with approximate angular response correction). Then, this cloud optical depth is used as input in the model to derive the direct to diffuse irradiance ratio for each spectral irradiance measurement, which is needed in the angular response correction algorithm (Bais et al., 1998). The model-derived cosine correction factor method was validated against the method that is regularly used after 1996 (Bais et al., 1998) using four years of Brewer \#086 data (1997-2000). The two methods were found to agree on the average within $\pm 1 \%$, regardless of season.

In Fig. 4, the mean angular response correction factors at $324 \mathrm{~nm}$ from all-sky and clear-sky spectra is presented for each instrument, as a function of the solar zenith angle. The shaded areas represent the $1 \sigma$ variability for the all-sky average correction factor. The respective variability of the clearsky correction factor is very close to that for all-sky, hence it is not shown here. Mean corrections for the Brewers \#086 and $\# 005$ are $7 \pm 1.5 \%(1 \sigma)$ and $11 \pm 2 \%(1 \sigma)$, respectively. This difference is due to the different angular responses of the two instruments as measured in the laboratory (Bais et al., 1998). The dependence of this factor on solar zenith angle is more evident under clear-sky conditions than under cloudy skies, where the solar zenith angle dependence is less than $1 \%$. The correction factors under clear skies are very similar to those under all skies because for small solar zenith angles (summer period) there is high probability of cloudless skies, whereas for large solar zenith angles the direct irradiance contributes less to the global irradiance.

\subsection{Temperature correction}

The Brewer spectrophotometer was developed primarily for measurements of the total ozone column (Kerr et al., 1980). These measurements are corrected regularly for the effects from changes in temperature, but, because the ozone algorithms are based on radiance ratios, temperature related changes to the instrument response are not critical, as long as the changes are independent of wavelength (Weatherhead et al., 2001). However, in the spectral irradiance measurements the temperature sensitivity of the Brewer is expected to be more apparent.

The internal temperature of the Brewer instruments is not controlled, as it happens with other UV spectroradiometers. However, to avoid operation at very low temperatures electrical heaters are used to automatically warm the interior of the instrument when its temperature falls below $\sim 7-10^{\circ} \mathrm{C}$. These heaters are usually capable of keeping the temperature above $0^{\circ} \mathrm{C}$, but they are not sufficiently strong to maintain this level if the ambient temperature is very low (e.g. lower than $\sim-10^{\circ} \mathrm{C}$ ). An electrical fan is also installed to help the air circulation inside the instrument enclosure, in order to minimize temperature gradients. In our Brewers these heaters were first installed in 1995, but occasionally 
they were not operating due to hardware failures. The internal temperature is sensed at three different spots, but only the temperature associated with the photomultiplier is recorded. At the site of Thessaloniki, the internal temperature of the instruments can vary during the year from about $0^{\circ} \mathrm{C}$ to more than $45^{\circ} \mathrm{C}$, depending on the ambient temperature and sunshine. Occasionally, temperatures a few degrees below zero and up to $55^{\circ} \mathrm{C}$ have been recorded.

It was suggested by Meltzer et al. (2000) that there are two main components contributing to the temperature dependence of the absolute spectral measurements of a Brewer: the photomultiplier tube (PMT) and the Nickel Sulphate $\left(\mathrm{NiSO}_{4}\right)$ filter that is used in MK II Brewers in front of the PMT to remove the high order refractions from the grating, allowing only radiation with wavelengths below $\sim 325 \mathrm{~nm}$ to be measured. The PMT sensitivity on temperature is generally wavelength independent. Therefore, the wavelength dependent part of the effect can be attributed to changes in the optical transmission of the extremely hygroscopic $\mathrm{NiSO}_{4}$ band-limiting filter (Bais et al., 1996). In the double monochromator Brewer \#086 no $\mathrm{NiSO}_{4}$ filter is used, as the spectrometer gratings operate in the first order, therefore there are no higher orders of refraction to be removed. Until now no temperature corrections have been applied to the data of the two Brewers, although several attempts to determine the temperature effects had been made in the past. Recently it was reported (Ylianttila and Schreder, 2005; McKenzie et al., 2005) that a number of Teflon diffusers are influenced by temperature changes, but since the temperature of the diffuser in the Brewers is not monitored, we could not take into account such an effect.

In this study, the temperature coefficients were calculated from various available data and methodologies, such as the history of internal standard lamp measurements and the histories of $50 \mathrm{~W}$ external lamp and $1000 \mathrm{~W}$ lamp measurements. In particular, the temperature coefficients resulting from the standard lamp measurements were calculated for days with at least four measurements, using linear regressions and assuming linearity in the temperature effects. The advantage of this method is that it provides a lot of information on the history of the temperature coefficients, which appear to vary with time. The main disadvantage is the lack of information on possible temperature effects on the operation of the internal standard lamps, including the electronic circuit that drives these lamps (Weatherhead et al., 2001).

Measurements of the external lamps $(50 \mathrm{~W}$ and $1000 \mathrm{~W})$ were also used for the estimation of temperature coefficients for the two instruments. The observed changes in the irradiance of a lamp recorded by the two Brewer spectroradiometers may be due to both the aging of the instrument and the temperature variations. Assuming that both effects are linear, a multi-linear regression may be used to calculate the temperature correction factor, in $\% /{ }^{\circ} \mathrm{C}$ (Weatherhead et al., 2001). From the above analysis we have taken into account only the results that are statistically significant. The temperature dependence of the Teflon diffuser could affect the temperature coefficients calculated by using external lamps, but as stated earlier, this dependence cannot be taken into account because the temperature of the diffuser is not monitored. On the contrary, when the internal standard lamps are used in the analysis there is no involvement of the diffuser.

Finally, we conducted a case study for both Brewers, by measuring a $1000 \mathrm{~W}$ working standard lamp at different instrument temperatures, under very stable and controlled conditions. In particular, the instruments were brought into the dark room in the early morning hours when the ambient temperature, hence its internal temperature, was low. The current and the voltage of the $1000 \mathrm{~W}$ lamp were electronically stabilized with a high precision controlling system. The instrument was set to perform sequential spectral measurements of the external $1000 \mathrm{~W}$ lamp and the internal standard lamp, while its internal temperature was rising during the day. The characterization test in the laboratory was repeated with each spectroradiometer at three different days, to ensure repeatability.

The main advantage of the laboratory test over the statistical estimation of the temperature coefficient from the time series of the lamps is that neither the lamp, nor the instrument are likely to change during one day. Therefore, the uncertainty of the laboratory method becomes negligible, and the only factor that may affect the measurements is the internal temperature of the Brewer. Thus the temperature correction factor can be easily derived from a linear regression. The disadvantage, on the other hand, is that this study is representative only for the current state of the instrument and does not provide any information for the past.

Brewer \#086 has shown high consistency in the results of the different methods. The temperature coefficient that resulted from the laboratory test was considered as the most representative due to the small uncertainty in the measurements. On the contrary, for Brewer \#005 the temperature coefficients that resulted from the standard lamp measurements record were different from those derived from the analysis of the $50 \mathrm{~W}$ lamp record as well as from the laboratory test. Taking into account the uncertainties of each methodology we decided to use the laboratory characterization test to determine the temperature coefficients for the single monochromator, as well.

In Fig. 5, the lamp irradiance measurements performed during the single day temperature characterization test for both Brewer spectroradiometers, are shown. The percentage deviation of the measurements at $320 \mathrm{~nm}$ from their mean is presented as a function of the internal temperature of the instruments. The different symbols represent the three days of measurements for each instrument. The slopes of the linear regressions on the data correspond to the respective temperature coefficients which are: $+0.065 \pm 0.03 \% /{ }^{\circ} \mathrm{C}$ for $\# 005$ and $-0.22 \pm 0.02 \% /{ }^{\circ} \mathrm{C}$ for $\# 086$. Note that the above temperature coefficients are valid only for the specific wavelength 

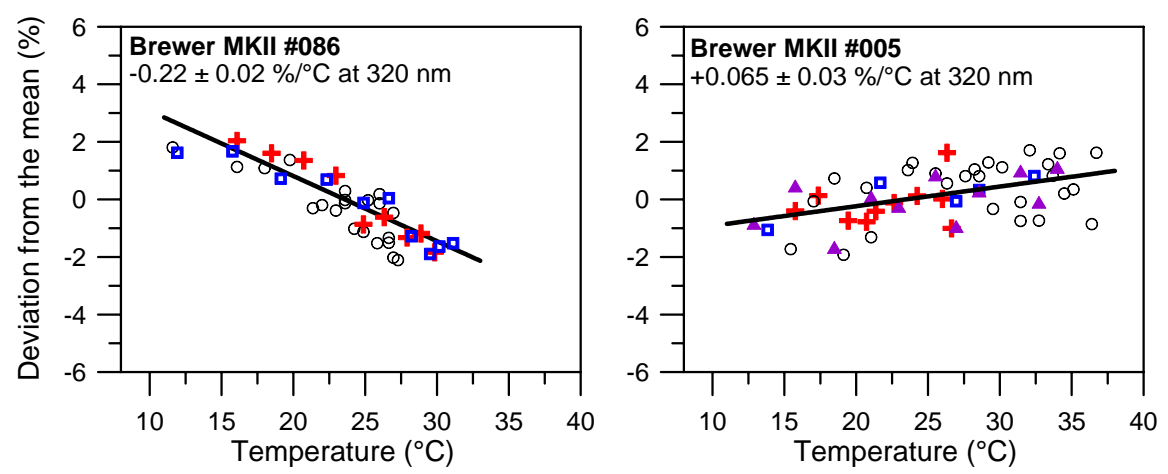

Fig. 5. Percentage deviation of lamp irradiance measurements at $320 \mathrm{~nm}$ from their mean, as a function of temperature. Measurements were performed in the laboratory using a $1000 \mathrm{~W}$ DXW lamp. The slopes of the regressions represent the temperature coefficients for each instrument, in $\% /{ }^{\circ} \mathrm{C}$.

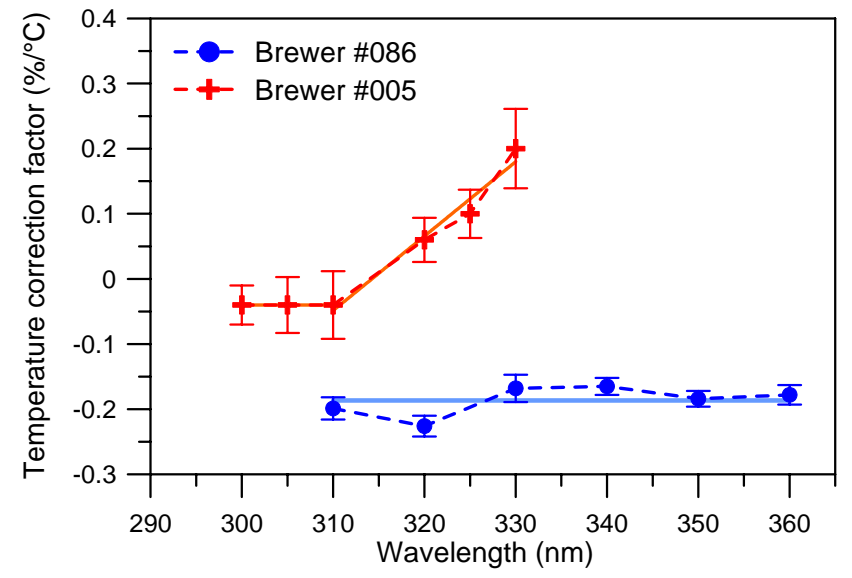

Fig. 6. Wavelength dependence of temperature correction factors for the two Brewer spectroradiometers, \#005 and \#086, derived from linear fits on lamp irradiance measurements conducted in the laboratory in December 2005.

displayed in Fig. 5. The temperature range during the experiment was $11-35^{\circ} \mathrm{C}$.

Figure 6 shows the wavelength dependence of the temperature correction factors, as derived from the laboratory characterization tests. Apparently, the temperature correction factor of Brewer \#005 is constant and equal to $-0.04 \% /{ }^{\circ} \mathrm{C}$ for wavelengths up to $310 \mathrm{~nm}$, increasing linearly thereafter. Brewer \#086 shows no spectral dependence in the correction factor, as expected due to the absence of the $\mathrm{NiSO}_{4}$ filter, thus the average value from all wavelength bands, $-0.188 \pm 0.025 \% /{ }^{\circ} \mathrm{C}$, was chosen as the temperature correction factor for all wavelengths.
The analysis of the external $50 \mathrm{~W}$ lamp measurements for Brewer \#086 showed a distinct change in the temperature coefficient in 1999, coinciding with the transportation of the instrument to an experimental campaign. Since no temperature characterization data existed for the period before 1999, we adjusted the temperature coefficient that was derived for the period after $1999\left(-0.188 \pm 0.02 \% /{ }^{\circ} \mathrm{C}\right)$, with the change calculated from the $50 \mathrm{~W}$ lamps. Thus for the period 19931999 a coefficient of $-0.06 \% /{ }^{\circ} \mathrm{C}$ is used. No such change in the level of the temperature correction factor for Brewer \#005 seems to have occurred.

Having established the temperature dependence of the two instruments, the entire data set was corrected for the effect of temperature variations. For each scan a temperature correction was calculated based on the difference in the temperature of the instrument during the particular scan, and its temperature during the absolute calibration that is used for this period. The temperature of the solar measurements appears to have an annual course following the annual variation of the ambient temperature, whereas the calibration temperature is less dependent on the ambient temperature, since the lamp measurements are performed in the dark room, where the air-temperature during a year ranges from 15 to $30^{\circ} \mathrm{C}$. Hence, the temperature correction of the measurements exhibits an annual course, as well.

The application of the temperature correction changed the solar irradiance measurements of Brewer \#086 by a factor ranging between $-1.4 \%$ and $+0.7 \%$ for the period $1993-$ mid 1999, and between $-4.7 \%$ and $+3 \%$ from 1999 onward. The correction of the solar measurements conducted by Brewer \#005 during the entire period of its operation is wavelength dependent, amounting, for example, to within $\pm 1 \%$ at $302.5 \mathrm{~nm}$ and $\pm 1.5 \%$ at $320 \mathrm{~nm}$. In Fig. 7, the monthly means of the temperature corrections in percent, applied on the two instruments' measurements, are presented. For Brewer \#005 only the correction at $320 \mathrm{~nm}$ is displayed. The shaded areas represent the $\pm 1 \sigma$ range of the mean correction. 


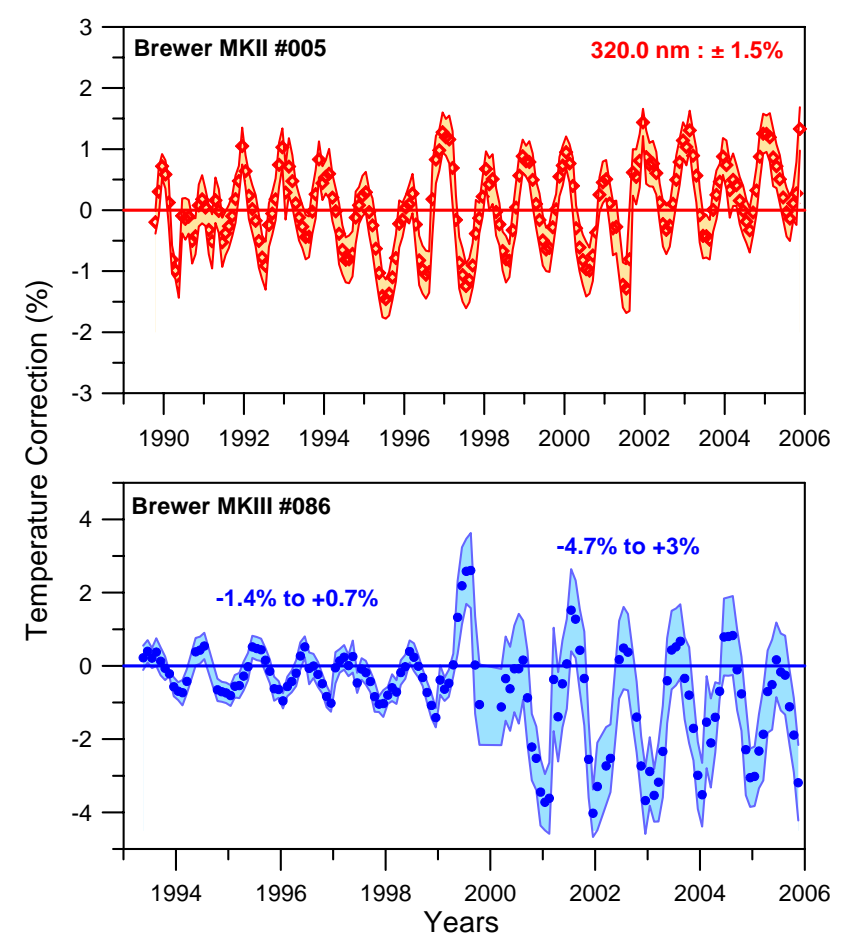

Fig. 7. Monthly means of the temperature corrections applied to the solar UV irradiance measurements conducted by the two Brewer spectroradiometers, during the entire period of their operation. The upper panel displays the correction for Brewer \#005 (at $320 \mathrm{~nm}$ ) and the lower panel the correction for Brewer \#086. The shaded areas represent the standard deviation $( \pm 1 \sigma)$ of the mean.

\section{Measurement uncertainties}

The overall uncertainties of the measurements were estimated following a methodology similar to that described in Bernhard and Seckmeyer (1999). Table 1 summarises the results of the uncertainty analysis from all sources of error that may affect the spectral measurements conducted by the two spectroradiometers. For Brewer \#005 the measurement uncertainty is presented for two wavelength bands because of the spectral dependence of the temperature correction and the stray light effect. In the following each source of uncertainty presented in Table 1, is discussed:

Absolute calibration:

The uncertainty of the absolute calibration procedure is estimated to $\pm 1.4 \%(1 \sigma)$, resulting from the combination of all known sources of uncertainty, including the stray light in the calibration room, the stability of the lamp current, and the adjustment of the distance of the lamp from the diffuser.

\section{Stray light:}

The stray light effect on the double monochromator Brewer \#086 measurements is considered negligible. Although the
Table 1. The sources of error that affect the spectral measurements of the two Brewer spectroradiometers and the associated uncertainties.

\begin{tabular}{llll}
\hline & Brewer \#086 & \multicolumn{2}{c}{ Brewer \#005 } \\
\hline Source of error & & $305 \mathrm{~nm}$ & $320 \mathrm{~nm}$ \\
\hline Absolute calibration & 1.40 & 1.40 & 1.40 \\
Stray light & 0.00 & 4.00 & 0.00 \\
Wavelength shift & 0.50 & 0.50 & 0.50 \\
Linearity & 0.28 & 0.28 & 0.28 \\
Radiometric Stability & 2.80 & 3.30 & 3.30 \\
Temperature correction & 1.00 & 0.84 & 1.56 \\
Angular response & 3.50 & 3.50 & 3.50 \\
\hline Combined Uncertainty $( \pm 1 \sigma)$ & $4.8 \%$ & $6.5 \%$ & $5.3 \%$ \\
\hline
\end{tabular}

measurements of Brewer \#005 are corrected for the stray light effect, as discussed in section 4.1, the measurements below $305 \mathrm{~nm}$ may still be contaminated. The average contribution of stray light at these wavelengths is estimated to about $4 \%$. This is evident in the comparison results of the two spectroradiometers measurements, which are discussed in Sect. 6.

Wavelength shift:

The wavelength shift of the spectral measurements has been determined by the application of the SHICrivm algorithm which reported wavelength shifts of the order of $\pm 0.1 \mathrm{~nm}$ at $300 \mathrm{~nm}$ and $\pm 0.05 \mathrm{~nm}$ at $320 \mathrm{~nm}$, for both instruments. According to Slapper et al. (1995), the uncertainty of the method is $\pm 0.02 \mathrm{~nm}$. Bais (1997a) reported that wavelength shifts of that order result in an irradiance change of $\sim 0.5 \%$, both at 305 and $320 \mathrm{~nm}$.

\section{Linearity:}

The linearity of the instruments' response was determined in the laboratory using attenuation filters and the associated uncertainty is estimated to $0.2 \%$. Since the departure from linearity affects the solar measurements, as well as the lamp measurements during the calibration, a combined uncertainty $(\sqrt{2} \times 0.2=0.28 \%)$ was used in Table 1 .

Radiometric stability:

According to Kostkowski (1997), the radiometric stability of an instrument is the standard deviation of the mean that results from a time series of the difference between consecutive absolute calibration factors. The radiometric stability was found $\sim 2.8 \%$ for Brewer \#086 and $\sim 3.3 \%$ for Brewer \#005.

Temperature correction:

The uncertainty due to temperature correction is a type B uncertainty (Bernhard and Seckmeyer, 1999) and it is 


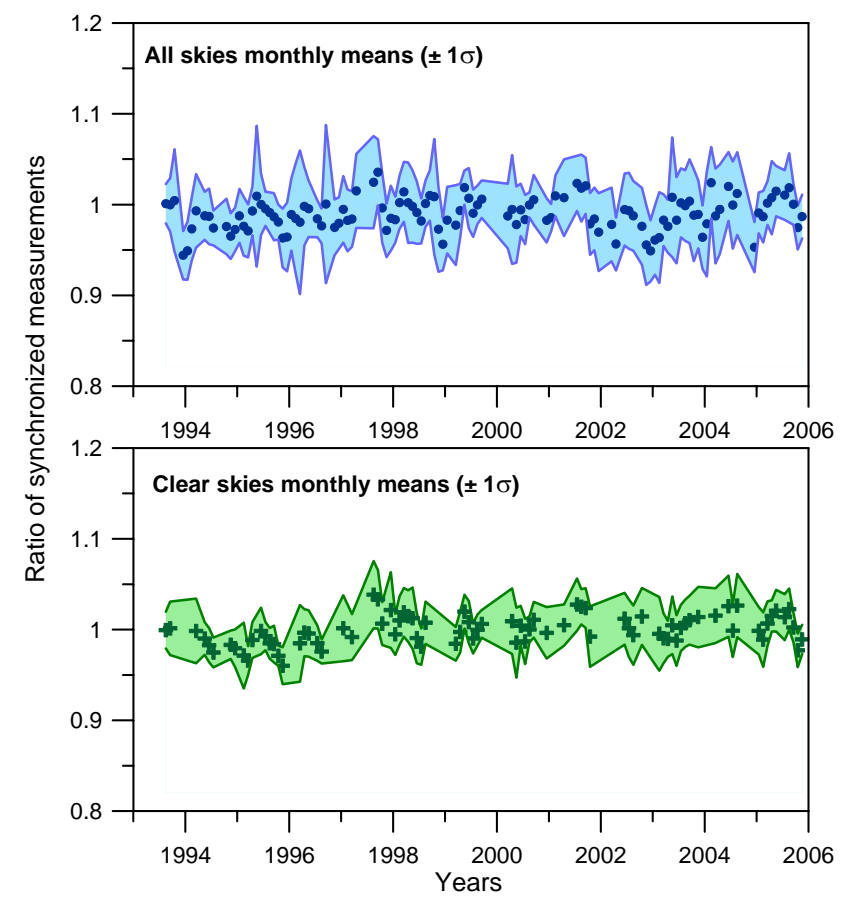

Fig. 8. Time series of monthly mean ratios (Brewer \#086 over Brewer \#005) formed by irradiance integrals $(315-320 \mathrm{~nm})$ recorded within $1 \mathrm{~min}$ by the two Brewer spectroradiometers at Thessaloniki, under all-sky (upper panel) and clear-sky (lower panel) conditions. The shaded envelope corresponds to the standard deviation $( \pm 1 \sigma)$ of the mean.

determined through the maximum and the minimum corrections applied to the measurements, as they are displayed in Fig. 7.

Angular response:

The uncertainty due to the angular response correction is the combined uncertainty of all sources of error involved in the procedure, namely, the uncertainty in the direct measurements, which is $\pm 2 \%$ (Bais, 1997b), the uncertainty in the determination of the angular response function, which is also $\pm 2 \%$ (Bais et al., 2005) and the uncertainty due to the isotropy assumption made for the determination of the correction factor of the diffuse irradiance, which is $\pm 2 \%$ as well. Thus, the combined uncertainty was estimated to $\pm 3.5 \%$.

As it is shown in Table 1, combining the uncertainties from all sources of error, an uncertainty of $\sim \pm 5 \%$ results for Brewer \#086, while for Brewer \#005 the uncertainty is estimated to $\pm 6.5 \%$ for $305 \mathrm{~nm}$ and $\sim \pm 5 \%$ for $320 \mathrm{~nm}$. All uncertainties correspond to $1 \sigma$.

\section{Comparison of measurements from the two Brewers}

Following the re-evaluation of the spectral solar UV measurements performed by the two Brewer spectroradiometers, a detailed comparison in the common spectral region of the two data sets was conducted. Specifically, we examined the ratios (Brewer \#086 over Brewer \#005) of quasi-synchronous spectral irradiance integrals over the wavelength range 315$320 \mathrm{~nm}$, starting in mid-1993, when the newest instrument, Brewer \#086, was installed. As the two instruments operate with independent schedules and their scanning times are also different, absolute synchronization could not be achieved. Thus, two measurements were considered as synchronous when they were conducted within 1 min. Reducing this time interval to $30 \mathrm{~s}$ reduces slightly the noise in the ratios (from 0.044 to 0.036 for the ratios under all-sky conditions and from 0.036 to 0.029 for the clear-sky ratios), but also results into a much smaller data set. Hence, we decided to work with the 1 minute interval ratios.

In Fig. 8, the time series of the ratio of monthly mean synchronized irradiance measurements from the two Brewers are presented, separately for all-sky and clear-sky conditions. The methodology for the categorization of the measurements in the two classes is described in Sect. 3.2. Ratios of monthly mean irradiance were calculated only if at least 30 synchronous observations were available. The general pattern of the ratios in the two panels is similar, being on the average $0.989 \pm 0.044$ for all-sky and $0.996 \pm 0.036$ for clearsky conditions. The variability in the ratio is caused mainly by the imperfect synchronization of the measurements and by small changes in the instruments' sensitivity, which is within the uncertainty of the measurements. The noise in the ratio is higher under all skies, as expected, due to the variability induced by the variation of clouds during the measurements period. In the following sections we discuss possible dependencies of these ratios on temperature, solar zenith angle, and wavelength.

\subsection{Dependence on temperature}

Here we investigate whether the comparison of the two instruments is affected by the variation of their internal temperature, and, consequently, whether the applied temperature corrections have improved the comparison. The irradiance integral ratios of the two Brewers were formed for both the temperature-corrected and the uncorrected measurements. In both cases, measurements under all skies have been used. Thereafter, these ratios were grouped according to the internal temperature of one of the instruments into bins of $10^{\circ} \mathrm{C}$, the first centred at $0^{\circ} \mathrm{C}$ and continuing with increments of $10^{\circ} \mathrm{C}$, up to $50^{\circ} \mathrm{C}$. For each group, the ratios were averaged, and these averages with the corresponding standard deviations $(1 \sigma)$ are displayed in Fig. 9. The minimum recorded temperature was $-9^{\circ} \mathrm{C}$ and the maximum $+54^{\circ} \mathrm{C}$. Also, in Fig. 9 the number of measurements used to form 
each temperature group is displayed as a bar chart, at the bottom of the graph.

The ratios corresponding to $20^{\circ} \mathrm{C}$ and $30^{\circ} \mathrm{C}$ are very close to unity because these measurements were recorded at temperatures similar to those that occurred during the absolute calibration of the instruments, and therefore, the calculated corrections are very small. For temperatures below $20^{\circ} \mathrm{C}$ and above $40^{\circ} \mathrm{C}$, the temperature corrected ratios are closer to unity than the uncorrected ratios, suggesting that the applied temperature corrections improved the measurements. This is further supported by the fact that the two instruments have temperature coefficients of different sign. The same conclusion is drawn if only the clear-sky mean ratios are used; however, the standard deviations are smaller. Some small remaining temperature effects that can be seen at very low temperatures can be attributed partly to the effect of the internal heaters, causing temperature gradients, despite the continuous mixing of the air with the internal fans. In addition, the small number of observations conducted under extremely low or high temperatures, may explain the relatively large standard deviations of the averages at extreme temperatures, as well as their departure from unity.

\subsection{Dependence on solar zenith angle}

Such dependence could be introduced mainly by inappropriate angular response correction, and possibly by nonlinearities in the instrument responses and uncertainties in the characterization of the angular responses. At shorter wavelengths, under-correction of Brewer \#005 data for stray light may also contribute to the solar zenith angle (SZA) dependence of the ratio. The dependence of the irradiance ratios (Brewer \#086 over Brewer \#005) to solar zenith angle variations was investigated in a similar way to the temperature dependence.

Here, we grouped the ratios of synchronous measurements according to the solar zenith angle at the time of the measurements, in bins and increments of $10^{\circ}$, starting from $20^{\circ}$. Averages of the ratios for each group are presented in Fig. 10 as a function of SZA, separately for clear-sky and all-sky conditions. It appears that there is practically no difference between clear-sky and all-sky data, apart from the expected reduction in the variability of the ratios recorded under clear skies. At the bottom of the figure, a bar chart indicates the number of observations for each group of solar zenith angles. It is evident that the smaller the solar zenith angle, the fewer the available observations in the data set, since measurements at small SZA occur only during summer, while measurements at SZA higher than $\sim 60^{\circ}$ are present all year long. At the very small and very large SZA, below $20^{\circ}$ and above $80^{\circ}$, there seems to be a reduction in the ratio by about $1.5 \%$. These discrepancies which, however, are within the uncertainties of the measurements, may be attributed either to nonlinearities (very high intensities at $20^{\circ}$ and very low at $80^{\circ}$ ) or to insufficient angular response corrections. For wavelength

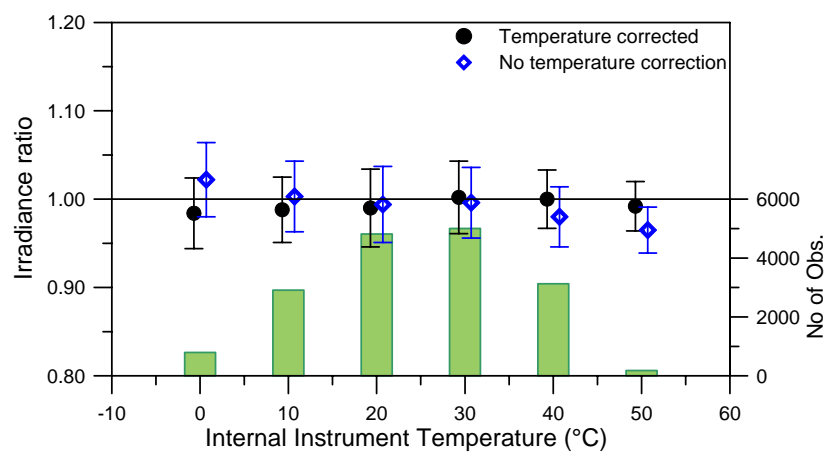

Fig. 9. Averages of the ratios (Brewer \#086 over Brewer \#005) of synchronous irradiance integrals $(315-320 \mathrm{~nm})$ recorded by the two Brewer spectroradiometers as a function of the internal instrument temperature, in bins of $10^{\circ} \mathrm{C}$. Filled circles correspond to temperature corrected data and rhombuses to data uncorrected for temperature effects. The error bars correspond to one standard deviation.

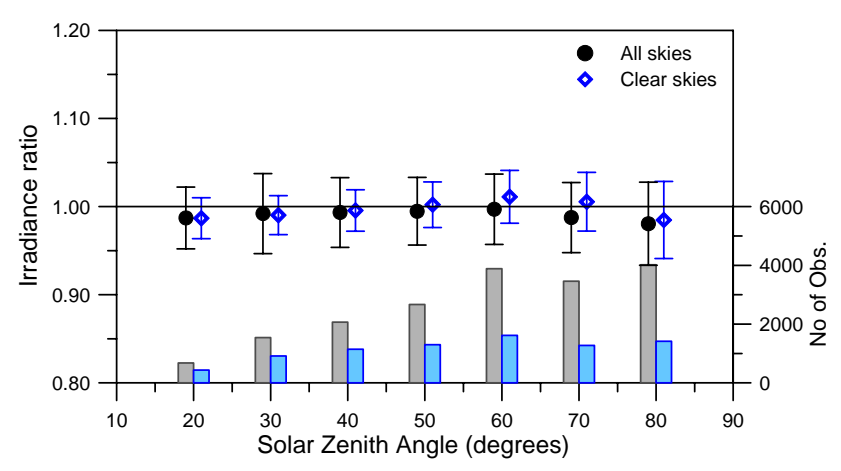

Fig. 10. Averages of the ratios (Brewer \#086 over Brewer \#005) of synchronous irradiance integrals $(315-320 \mathrm{~nm})$ recorded by the two Brewer spectroradiometers as a function of solar zenith angle, in intervals of $10^{\circ}$, for clear-sky (rhombuses) and all-sky conditions (filled circles). The error bars correspond to one standard deviation.

bands that are affected by the possible under-correction for the stray light effect, especially the 300-305 nm band (not shown here), the solar zenith angle dependence of the ratio is more evident. At large SZA the irradiance at short wavelengths is diminished; hence the contribution of stray light to the measured irradiance is more important than it is at smaller SZA.

\subsection{Wavelength dependence of the comparison}

Ratios of irradiance integrals (Brewer \#086 over Brewer \#005) were formed also for other wavelength bands, besides the $315-320 \mathrm{~nm}$ band, that was discussed so far. The comparison results between the two instruments (averages and standard deviations of their ratio) for all common $5 \mathrm{~nm}$ bands 
Table 2. Average and standard deviation of the ratio of irradiances measured synchronously by the two Brewer spectroradiometers, \#086 and \#005, integrated over $5 \mathrm{~nm}$ wavelength bands.

\begin{tabular}{lcc}
\hline \multirow{2}{*}{ Wavelength band $(\mathrm{nm})$} & \multicolumn{2}{c}{$\begin{array}{c}\text { Mean irradiance ratio } \\
(\text { Br. \#086 / Br. \#005) } \pm 1 \sigma\end{array}$} \\
\cline { 2 - 3 } & All skies & Clear skies \\
\hline $300-305$ & $0.955 \pm 0.095$ & $0.964 \pm 0.071$ \\
$305-310$ & $0.975 \pm 0.046$ & $0.982 \pm 0.040$ \\
$310-315$ & $0.993 \pm 0.043$ & $0.998 \pm 0.036$ \\
$315-320$ & $0.989 \pm 0.044$ & $0.996 \pm 0.036$ \\
$320-325$ & $0.991 \pm 0.044$ & $1.000 \pm 0.037$ \\
\hline
\end{tabular}

are summarized in Table 2, separately for all-sky and clearsky conditions.

For the all skies ratios, the irradiance integrals in the spectral bands $300-305 \mathrm{~nm}$ and $305-310 \mathrm{~nm}$ exhibit a deviation from unity by $-4.5 \%$ and $-2.5 \%$, respectively, which can be attributed to a possible under-correction of the single monochromator data for the stray light effect. The corresponding deviations in the clear-sky ratios are respectively $-3.6 \%$ and $-1.8 \%$. The reduction in the standard deviation with increasing wavelength is possibly due to the reduction in the noise of the measurements from both instruments as their sensitivity and the irradiance level increases with wavelength.

The data sets of the two Brewer spectroradiometers are not completely independent, as they share the same calibration sources. In addition, their comparison was used during the re-evaluation procedure to detect changes that were not identified from the inspection of the calibrations. On the other hand, the two instruments operate independently and they are different with respect to their wavelength sensitivity (\#005 has maximum sensitivity at about $305 \mathrm{~nm}$, decreasing rapidly with increasing wavelength, while the sensitivity of \#086 peaks at about $320 \mathrm{~nm}$ and decreases with decreasing wavelength). Therefore, the agreement that has been achieved in their irradiance measurements is good, for the stated levels of uncertainty. This allows merging of the two datasets to derive a composite spectral irradiance record.

\section{Summary and conclusions}

The re-evaluation of the solar irradiance measurements performed by two collocated Brewer spectroradiometers at Thessaloniki, Greece, was presented and discussed. For the re-evaluation, the calibration histories of the two instruments were re-visited and comparisons of their raw data were used to identify gaps that had not been detected by the quality con- trol procedures, as well as unreasonably high or low measurements caused by instrumental failures. The latter was supported also by comparison to a collocated erythemal radiometer. Finally, the data from both instruments were corrected for effects from temperature variations and for deviations from the ideal angular response.

The angular response corrections increased the irradiance measurements of Brewer \#086 by $7 \pm 1.5 \%(1 \sigma)$ and of Brewer \#005 by $11 \pm 2 \%(1 \sigma)$. The application of temperature corrections changed the measurements of Brewer \#086 at all wavelengths by $\pm 1.4 \%$ during the period $1993-$ mid 1999 and from $-4.7 \%$ to $+3 \%$ since 1999 . For Brewer \#005, the temperature correction changed the irradiance measurements on the average by $\pm 1 \%$ at $302.5 \mathrm{~nm}$ and $\pm 1.5 \%$ at $320 \mathrm{~nm}$. The combined uncertainty of the measurements was estimated, taking into account all the known sources of errors, including the absolute calibration procedure, the corrections for the temperature effects and the non ideal angular response, and the wavelength shift. The total uncertainty of the measurements was found $\pm 5 \%$ for Brewer \#086, while for Brewer \#005 it was estimated $\pm 6.5 \%$ at $305 \mathrm{~nm}$ and $\sim 5 \%$ at $320 \mathrm{~nm}$.

The comparison of synchronous irradiance measurements from the two instruments during their common period of operation, showed an overall agreement of about $1 \pm 4 \%$. Part of the differences can be attributed to lack in absolute synchronization of the measurements, which becomes important especially under partly cloudy conditions, and at large solar zenith angles. Taking into account their uncertainties, the agreement of the two instruments is satisfactory. The irradiance ratio of the two instruments showed no significant dependence on solar zenith angle or on internal instrument temperature. In addition, the ratio was rather stable with wavelength, except for wavelengths shorter than about $305 \mathrm{~nm}$, where an overestimation of the single monochromator Brewer by up to $4.5 \%$ was found, caused probably by insufficient correction of the stray light.

The detection of long term changes in surface irradiance depends largely on the long term stability of the instrument's sensitivity, and on the ability of the calibration procedures to compensate the sensitivity changes. We believe that the agreement that was achieved between the measurements of the two spectroradiometers, supported also by the level of agreement with a collocated broadband radiometer, is sufficient to justify the use of the re-evaluated 15 -year record for the analysis of long term variations of UV irradiance at Thessaloniki. The results from this ongoing analysis will be reported in a separate publication. 
Acknowledgements. This study was co-funded by the Ministry of National Education and Religious Affaires through the Project EPEAEK II - "Herakleitos" (Contract No. MIS 88740), which is co-funded by the European Union/European Social Fund, and by the European Commission through the Integrated Project SCOUTO3 (Contract No. 505390-GOCE-CT-2004).

We thank the two reviewers for their useful comments, which helped in improving the quality of the paper.

Topical Editor F. D'Andrea thanks W. Josefsson and another referee for their help in evaluating this paper.

\section{References}

Andrady, A., Aucamp, P. J., Bais, A. F., Ballare, C. L., Bjorn, L. O., Bornman, J. F., Caldwell, M., Cullen, A. P., Erickson, D. J., deGruijl, F. R., Hader, D.-P., Ilyas, M., Kulandaivelu, G., Kumar, H. D., Longstreth, J., McKenzie, R. L., Norval, M., Redhwi, H. H., Smith, R. C., Solomon, K. R., Sulzberger, B., Takizawa, Y. , Tang, X., Teramura, A. H., Torikai, A., van der Leun, J. C., Wilson, S. R., Worrest, R. C., and Zepp, R. G.: Environmental effects of ozone depletion and its interactions with climate change: Progress report, 2005, United Nations Environment Programme, Environmental Effects Assessment Panel, doi10.1039/b515670j, Photochem. Photobiol. Sci., 5, 13-24, 2006.

Bais, A. F., Zerefos, C. S., and McElroy, C. T.: Solar UVB measurements with the double- and single- monochromator Brewer Ozone Spectrophotometers, Geophys. Res. Lett., 23, 833-836, 1996.

Bais, A. F.: Spectrometers: Operational errors and uncertainties, in: Solar Ultraviolet Radiation, Modelling, Measurements and Effects, edited by: Zerefos, C. S. and Bais, A. F., NATO-ASI Series, 52, 165-174, 1997a.

Bais, A. F.: Absolute spectral measurements of direct solar ultraviolet irradiance with a Brewer spectrophotometer, Applied Optics, 36, 5199-5204, 1997b.

Bais, A. F., Kazadzis, S., Balis, D., Zerefos, C. S., and Blumthaler, M.: Correcting global solar ultraviolet spectra recorded by a Brewer spectroradiometer for its angular response error, Applied Optics, 37, 6339-6344, 1998.

Bais, A. F., Gardiner, B. G., Slaper, H., Blumthaler, M., Bernhard, G., McKenzie, R., Webb, A. R., Seckmeyer, G., Kjeldstad, B., Koskela, T., Kirsch, P., Gröbner, J., Kerr, J. B., Kazadzis, S., Leszczynski, K., Wardle, D., Brogniez, C., Josefsson, W., Gillotay, D., Reinen, H., Weihs, P., Svenoe, T., Eriksen, P., Kuik, F., and Redondas, A.: The SUSPEN intercomparison of ultraviolet spectroradiometers, J. Geophys. Res., 106, 12 509-12 526, 2001.

Bais A. F., Kazadzis, S., Garane, K., Kouremeti, N., Gröbner, J., Blumthaler, M., Seckmeyer, G., Webb, A. R., Koskela, T., Görts, P., and Schreder, J.: Portable device for characterizing the angular response of UV spectroradiometers, Applied Optics, 44, 7136-7143, 2005.

Bartlett, L. M. and Webb, A. R.: Changes in ultraviolet radiation in the 1990s: Spectral measurements from Reading, England, J. Geoph. Res., 105, 4889-4893, 2000.

Bernhard, G. and Seckmeyer, G.: Uncertainty of measurements of spectral solar UV irradiance, J. Geophys. Res., 104, 14312$14345,1999$.
Booth, R. C., Lucas, T., Morrow, J., Weiler, S., and Penhale, P.: The United States National Science Foundation/Antarctic Program's network for monitoring ultraviolet radiation, in: Ultraviolet Radiation and Biological Research in Antarctica, in: Antarct. Res. Ser., 62, edited by: Weiler, S. and Penhale, P., AGU, Washington D. C., 1994.

Brewer, A. W.: A replacement for the Dobson Spectrophotometer?, Pure and Appl. Geoph., 106, 919-927, 1973.

Capellani, F. and Kochler, C.: Temperature effects correction in a Brewer MKIV spectrophotometer for solar UV measurements, J. Geophys. Res., 105, 4829 - 4831, 1999.

Davies, J. A.: Correcting for stray light in Brewer spectroradiometers, Environmental Technology, 17, 421-426, 1996.

Feister, U., Grewe, R., and Gericke, K.: A method for correction of cosine errors in measurements of spectral UV Irradiance, Solar Energy, 60, 6, 313-332, 1996.

Gardiner, B. G. and Kirsch, P. J. (eds.): First European intercomparison of ultraviolet spectroradiometers, Air Pollution Research Report 38, CEC, Brussels, 1992.

Gardiner, B. G. and Kirch, P. J.: Setting standards for European spectroradiometers, Air Pollution Research Report 53, CEC, Brussels, 1995.

Gröbner, J., Wardle, D. I., McElroy, C. T., and Kerr, J. B.: Investigation of the wavelength accuracy of Brewer spectrophotometers, Applied Optics, 37, 36, 8532-8360, 1998.

Gröbner, J., Schreder, J., Kazadzis, S., Bais, A. F., Blumthaler, M., Görts, P., Tax, R., Koskela, T., Seckmeyer, G., Webb, A. R., and Rembges, D.: Traveling reference spectroradiometer for routine quality assurance of spectral solar ultraviolet irradiance measurements, Applied Optics, 44, 25, 5321-5331, 2005.

Harris, N. R. P.: Trends in stratospheric and free tropospheric ozone, J. Geophys. Res., 102, 1571-1590, 1997.

Huber, M., Blumthaler, M., and Ambach, W.: Method for determining the wavelength shift for measurements of solar UV-radiation, edited by: Stamnes, K. H., Proc. SPIE, 2049, 354-357, Atmospheric Radiation, 1993.

Kerr, J. B., McElroy, C. T., and Olafson, R. A.: Measurements of Ozone with the Brewer Ozone Spectrophotometer, in: Proceedings of Quadrennial Ozone Symposium, edited by: London, J., Boulder, Colorado, 74-79, 1980.

Kerr, J. B., McElroy, C. T., Wardle, D. I., Olafson, R. A., and Evans, W. F. J.: The automated Brewer spectroradiometer, in: Proceedings of Quadrennial Ozone Symposium on Atmospheric Ozone, Halkidiki, Greece, 396-401, 1984.

Kerr, J. B. and McElroy, C. T.: Evidence for large upward trends of ultraviolet $-\mathrm{B}$ radiation linked to ozone depletion, Science, 262, 1032-1034, 1993.

Kostkowski, H. J.: Reliable Spectroradiometry, Spectroradiometry Consulting, La Plata, Maryland, USA, 1997.

Mayer, B., Seckmeyer, G., and Kylling, A.: Systematic long-term comparison of spectral UV measurements and UVSPEC modeling results, J. Geophys. Res., 102, 8755-8767, 1997.

McKenzie, R., Badosa, J., Kotkamp, M., and Johnston, P.: Effects of the temperature dependence in PTFE diffusers on observed UV irradiances, Geophys. Res. Lett., 32(6), 1-5, 2005.

Meinander, O., Josefsson, W., Kaurola, J., Koskela, T., and Lakkala, K.: Spike detection and correction in Brewer spectroradiometer ultraviolet spectra, Optical Engineering, 42, 6, 1812-1819, 2003.

Meltzer, R. S., Wilson, A., Kohn, B., and Rives, J. E.: Temperature 
dependence of the spectral response for the MKIV Brewers in the UGA/USEPA network, 6th Brewer Workshop, Tokyo, Japan, 2000.

Metz, B., Kuijpers, L., Solomon, S., Andersen, S. O., Davidson, O., Pons, J., de Jager, D., Kestin, T., Manning, M., and Meyer, L. (eds.): Special Report of the Intergovernmental Panel on Climate Change (IPCC), Cambridge Univ. Press, UK, 2005.

Seckmeyer G. and Bernhard, G.: Cosine error correction of spectral UV-irradiances, in: Atmospheric Radiationtion, edited by: Stamnes, K. H., Proc. SPIE 2049, 140-151, 1993.

Seckmeyer, G., Mayer, B., Erb, R., and Bernhard, G.: UVB in Germany higher in 1993 than 1992, Geophys. Res. Lett., 21, 577580, 1994.

Seckmeyer, G., Bais, A., Bernhard, G., Blumthaler, M., Eriksen, P., McKenzie, R. L., Roy, C., and Miyauchi, M.: Instruments to measure solar ultraviolet radiation, part I: spectral instruments, WMO-GAW report, Geneva, Switzerland, 2001.

Slaper, H. H. A. J. M., Reinen, M., Blumthaler, M., Huber, and Kuik, F.: Comparing ground-level spectrally resolved UV measurements from various instruments: A technique resolving effects of wavelength shifts and slitwidths, Geophys. Res. Lett., 22, 2721-2724, 1995.

Slaper, H., and Koskela, T.: Methodology of intercomparing spectral sky measurements, correcting for wavelength shifts, slit function differences and defining a spectral reference, in: the Nordic Intercomparison of Ultraviolet and Total Ozone Instruments at Izana, edited by: Kjeldstad, B., Johnson, B., and Koskela, T., Finn. Meteorol. Inst., Helsinki, 89-108, 1997.
Vasaras, A., Bais, A. F., Feister, U., and Zerefos, C. S.: Comparison of two methods for cloud flagging of spectral UV measurements, Atmos. Res., 57, 1, 31-42, 2001.

Weatherhead, E., Theisen, D., Stevermer, A., Enagonio, J., Rabinovitch, B., Disterhoft, P., Lantz, K., Meltzer, R., Sabburg, J., DeLuisi, J., Rives, J., and Shreffler, J.: Temperature dependence of the Brewer ultraviolet data, J. Geophys. Res., 106, $34121-$ $34129,2001$.

Webb, A. R., Gardiner, B. G., Martin, T. J., Leszcynski, K., Metzdorf, J., and Mohnen, V. A.: Guidelines for Site Quality control of UV monitoring, WMO-GAW report No. 126, Geneva, Switzerland, 1998.

Webb, A. R., Gardiner, B. G., Leszczynski, K., Mohnen, V., Johnston, P., Harrison, N., and Bigelow, D.: Quality Assurance in monitoring solar ultraviolet radiation: state of the art, WMO/GAW No. 146, Geneva, Switzerland, 2003.

Ylianttila, L. and Schreder, J.: Temperature effects of PTFE diffusers, Optical Materials, 27, 1811-1814, 2005.

Zerefos, C. S., Balis, D. S., Bais, A. F., Gillotay, D., Simon, P. C., Mayer, B., and Seckmeyer, G.: Variability of UV-B at four stations in Europe, Geophys. Res. Lett., 24, 1363-1366, 1997.

Zerefos, C., Balis, D., Tzortziou, M., Bais, A., Tourpali, K., Meleti, C., Bernhard, G., and Herman, J.: A note on the interannual variations of UV-B erythemal doses and solar irradiance from ground-based and satellite observations, Ann. Geophys., 19, 115-120, 2001, http://www.ann-geophys.net/19/115/2001/. 